\title{
Different Approaches for Making the Initial Selection of Talented Students in Programming Competitions
}

\author{
Bojan KOSTADINOV, Mile JOVANOV, Emil STANKOV, \\ Marija MIHOVA, Biljana RISTESKA STOJKOSKA \\ Faculty of Computer Science and Engineering, University Ss. Cyril and Methodius \\ st. Rugjer Boshkovikj 16 Skopje, Macedonia \\ e-mail: bojan.kostadinov@gmail.com,\{mile.jovanov,emil.stankov, \\ marija.mihova,biljana.stojkoska\}@finki.ukim.mk
}

\begin{abstract}
Competitions in informatics are one of the most useful ways of engaging pupils to the field of computer science. Many national and international competitions are carried out each year, with the organizers of each of them attempting to reach out to as many potential students as possible. In this paper, we analyse several different contest types, how each of them aids to promote computer science by engaging students in competitions, and how they can help provide the initial selection of talented students for the later stages of the competitions. Based on that, we propose seven criteria for the classification of the contests. Further we present our rich experience in the organization of Macedonian contests. Finally, we propose different approaches for making the initial selection of talented students in programming competitions and discuss ways for alleviating some of the issues with standard contests, for example enabling feedback and introducing difficulty divisions.
\end{abstract}

Keywords. programming contests, types of contests, promoting informatics, identifying talented students.

\section{Introduction}

In this paper, we will show several approaches for attracting talented students interested in participating in informatics workshops or contests, and conducting an initial selection between them. Although the focus of this paper is mostly targeted at the organization of competitions in informatics, the presented ideas can also be used by educational organizations and governmental entities to identify talented students in the STEM (Science, Technology, Engineering and Math) fields. As the demand for skilled workers in science, technology and mathematics increases, linking the rise of these fields with global competitiveness, it's increasingly vital that governments and institutions find 
ways to detect talented students early on in their primary and secondary education. Because identifying potentially gifted and talented students has never been an exact science (Goodhew, 2009), making it difficult to measure and analyse, we will present several different kinds of approaches to this problem, as well as the advantages and disadvantages of every one of them.

The paper is organized as follows. In Section 2 we will present several popular competitions that are currently organized throughout the world, and attempt to provide a general overview of possible contest types and the advantages and disadvantages of each of them. We present this through seven criteria that we identified, and which we propose for the purpose of classification of contests. In Section 3 we focus on the types of informatics competitions organized by the Computer Society of Macedonia, compare them with the international contests, and describe the biggest challenges that we are facing at the moment. We will also briefly describe several other contests that take place in our country. Section 4 builds up on the details presented in the previous sections, and compares how suited each contest type is to the problem of attracting pupils, and making an initial selection between them. In Section 5 we provide directions for future work and summarize our findings.

\section{Overview of Contests}

Competitions are a major factor in education (Verhoeff, 1997). A lot of countries use different forms of competitions in order to encourage students to perform better in school (for example, in order to earn scholarships or grants), to bring the best out of them (by enrolling students into special programs based on their interests), or to promote cooperation by grouping students into teams and teaching them (through competitions) the importance of collaboration between people with different talents and preferences.

Whatever the goal is, competitions must be fair in order to make them engaging to students (or people, in general). That is, students should have (pretty much) the same chances of winning - compared to other students/teams. In this paper we describe several competition types that satisfy these criteria - including competitions that are graded manually (by people), or automatically (by machines).

Besides fairness, a very important attribute of competitions is how well they accommodate to the different skills possessed by students. With regards to informatics competitions, they should be designed in such a way that the difficulty of (at least some of the) problems is approachable to most of the students. This can be achieved by dividing students into age divisions, knowledge groups, or by organizing a series of contests with increasing difficulty.

Before we attempt to define the criteria by which competitions can be reviewed, we will first provide an overview of several active informatics competitions. We will use this overview, as well as our knowledge about other contests, to describe strategies for dividing, analysing and improving competitions.

In the following list, we present some of the most popular, and some of the most interesting competitions organized in the world today. Although they have different grad- 
ing criteria, deliverables or durations, each one of them motivates and attracts a large number of participants every year.

- The International Olympiad in Informatics (IOI) is an annual programming competition, reserved for secondary school students. Students compete by solving problems (of algorithmic nature) in one of several available programming languages (C, C++, Pascal and, starting from 2015 - Java). In the last few years, participants receive full feedback for their submissions, which wasn't the case during earlier Olympiads. The contest is usually organized on two competition days, and countries are limited to 4 competitors each.

- ACM International Collegiate Programming Contest (ACM-ICPC) is an annual programming competition involving university teams. The competition is initially organized in several regions, with regional winners attending the World Finals. During a contest, the teams are given several hours (usually 5) to solve multiple programming tasks using one of the available programming languages (C, $\mathrm{C}++$, or Java). Teams receive feedback when they submit a wrong solution for a task, allowing them to make changes to their solution and submit a new one.

- Google Code Jam is an international programming competition, initially created as a means to identify top engineering talent for potential employment at Google. Participants are given several tasks that they need to solve, using any programming language and development environment. Currently, competitors receive an input file, for which they must generate a correct output in a limited amount of time. For most of the tasks, there are actually two input files - an easy input (for which feedback is provided), and a hard input (which is judged after the contest has finished).

- Bebras is a very popular international competition, whose goal is to promote informatics and computer science to students of various ages. The contests are made up of a set of short questions, which can be answered - according to the organizers - without prior knowledge about informatics, even though the tasks are clearly related to informatics concepts, and are designed to motivate students in computational thinking.

- Infomatrix is an International Informatics Project Competition organized to encourage young people to apply their creativity, imagination and passion to make a difference in the world through technology. The competition reached more than 60 countries and 460 schools in 2014. Students can compete in 5 categories: Programming, Computer Art, Hardware Control, Short movie and Robotics (Mini Sumo, Line Follower, Lego Sumo and Lego Line Follower). Some of the criteria by which projects are judged in the Programming, Computer Art, Hardware Control and Short movie area are: Originality, Quality of the project documentation and the content, Usability, as well as whether or not the project reflects the current interests in the specific area.

- The Australian Informatics Competition (AIC) is a pen-and-paper style competition, organized as an entry-level competition in informatics in Australia. Questions are designed to test algorithmic ability, logic and the students' ability to analyse algorithms. Since its introduction in 2005 , the number of students that 
take part in the competition has increased from 2000 students, to more than 7000 students in the last year (Clark and Clapper, 2014).

When defining the scope and rules for a competition, organizers can decide to give students either a predefined set of tasks (or questions) to complete, or they can give broad definitions of topics, and require students to showcase their own projects or work. For competitions where students work on a predefined set of programming tasks or questions, the grading is usually much easier and faster - in some cases, even automated using specialized grading systems. Participants either upload their solutions to an online system, or they write them down (or mark answers) using pen and paper. For competitions based on projects, a judging committee formed by the organizer usually does the grading manually (Magdin and Turcani, 2015).

Contests can be classified according to multiple criteria. There is no substantial previous work on this matter. After a careful review of the work in (Pohl, 2006), and a look at the rules of multiple competitions around the world, we propose a classification that we believe is useful with regards to currently popular competitions in informatics (both in our country and internationally).

Competitions in informatics can be roughly classified by these seven criteria:

- What participants need to work on (types of problems/tasks given to the contestants)?

- What do participants need to deliver?

- How will participants provide their output/product (submission method)?

- What is the duration of the competition?

- What is the scoring system?

- How is the grading done?

- What sort of feedback do participants get during the competition?

Some of the more popular options for each criterion are presented in Table 1.

Compared to previous research work on the overview of competitions in informatics, we chose to give feedback a lot more emphasis. Feedback is one of the most important parts of a competition. For most programming competitions, the increasing trend is to provide participants with some sort of feedback regarding the correctness of their solutions. One of the bigger issues of the International Olympiad in Informatics

Table 1

Criteria for classifying competitions in informatics

\begin{tabular}{ll}
\hline Criterion & Possibilities \\
\hline Problems & Project, Set of tasks, Set of questions, Mixed \\
Deliverables & Answers, Source Code, Executable, Working Robot \\
Submission method & Pen and paper, files on an USB drive, online grading system \\
Duration & Short competition, Long/marathon competition \\
Scoring & Equal points for each task (question), different points, scoring based on \\
how quickly the task is solved & Manual, Semi-automatic, Automatic \\
Grading & No feedback, Partial feedback, Full feedback, Pointing out mistakes, etc. \\
Feedback &
\end{tabular}


(and the organization of national competitions for selecting the top students for the IOI) has been that the automatic grading process may be unfair - since small mistakes may lead to solutions which score very few points (especially for tasks which are hard to test/ debug during the limited competition time), and good competitors can end up with bad results. Providing feedback during the competition is one good solution to this problem, although one has to consider that the feedback may influence the goals and form of the contest.

Programming competitions can be easily classified using the criteria provided above. Thinking about the possible criteria and how they can be amended for a given competition can lead to better communication between organizers and participants, to fairer grading, and ultimately to the organization of better competitions.

There are hundreds of different informatics competitions organized each year (by a wide range of organizers), and each of them needs to properly inform participants about the terms of the competition, and what exactly is expected from them. As an example, the International Olympiad in Informatics is a competition where: (1.) students work on a predefined set of tasks created by the organizers, and are asked to (2.) deliver their source code, by means of (3.) uploading it to an online contest system, (4.) during a limited competition round of 5 hours, where (5.) each task is worth the same amount of points, and the provided solutions are (6.) graded automatically using a contest management system. Although results are published after the competition is done, (7.) students receive feedback for their own solutions while the competition is running. It is worth pointing out that before deciding on a competition type on the basis of the criteria presented above, organizers must first take into account the available resources, the competition's goal, and the expected number of participants.

\section{Macedonian National Competitions in Informatics}

Competitions in informatics are held in Macedonia since 1990, and, by the end of 2014, there were 25 national contest cycles - which include multiple competitions each year, selection contests for international competitions, as well as training camps. Every year the contestants go through many levels of competition so that the best could be selected. The selected pupils represent themselves and Macedonia at the (Junior) Balkan Olympiad in Informatics (BOI/JBOI), the International Olympiad in Informatics (IOI), and at other smaller regional competitions. The main organizer of the competitions in informatics for primary and secondary school pupils is the Computer Society of Macedonia.

The format of the competitions evolves each year, depending on many factors, such as the number of interested pupils, available resources, inclusion of programming in the school's curricula, etc. The interest for the competitions in informatics, presented by the number of participants at each competition level, is presented in Table 2. Presently, the competitions are organized for primary and secondary school pupils, and include: School Qualification Competition, Regional/Municipality Competition, National Competition, National Olympiad, and (potentially) Selection Contests for International Competitions. 
Table 2

Number of students participating in the official competitions in informatics in Macedonia

\begin{tabular}{lllrrrr}
\hline & \multicolumn{1}{l}{ Year } & & & & & \\
\cline { 2 - 7 } & 2009 & 2010 & 2011 & 2012 & 2013 & 2014 \\
\cline { 2 - 7 } Regional competition & 51 & 55 & 118 & 209 & 290 & 341 \\
National competition & 44 & 45 & 68 & 95 & 118 & 101 \\
National Olympiad & 22 & 23 & 19 & 21 & 21 & 21 \\
\hline
\end{tabular}

In order to support several competition types, enable a large number of students to participate in the competitions, and introduce as many pupils as possible to the art of programming, all of the competitions in informatics that are part of the national contest cycle (accredited by the Ministry of Education), are organized using the MENDO competition management system (Kostadinov et al., 2010).

The usage of a grading system has a lot of advantages with regards to the organization of programming competitions, but it also has several disadvantages. Specifically, MENDO is an interactive e-learning system that was developed following the goal of integration of all previously used modules for organization of programming contests, in a single compact environment: supporting the uploading of the competition tasks (organizers) and the solutions (contestants), evaluation and automatic grading of the uploaded solutions, publishing results, communication, training, lectures intended for learning programming languages and student improvement, collaboration, and feedback. In order to provide automatic grading, students solve the tasks by writing a solution (usually a console program) in one of several available programming languages, which is later compiled, added to a grading queue, and eventually executed on several test cases by sending various input data, whilst time, memory, output and security limits are being enforced on top of it. The system's support for multiple contest types allows us to organize different competitions each year (Jovanov et al., 2013).

Tasks are a powerful way to test the user's knowledge, but they can also influence users in a negative way - for example, a student can be stuck on a certain task due to inexperience (printing data in a wrong format, etc.). In order to help users, MENDO offers several means of providing feedback (during training or competitions): solution-specific analysis to match problems with a predefined set of mistakes, the ability to download or examine test cases, and the option to view the author's solution to a task. This helps us to attract new participants without much involvement from their principals and tea-chers, and to keep them interested in practicing without worrying that they can get stuck on specific tasks. The number of sent and graded submissions by students, on the MENDO system, increases each year, as can be seen on Fig. 1.

The usage of a grading system and competitions based on solving programming tasks helps the Computer Society of Macedonia organize competitions in a similar environment to the one available at the International Olympiad in Informatics. In reality, as long as the international competitions in informatics are organized as they are, in order to select the best students for the international competitions, the national contests need to accept similar grading and organizational practices. However, organizing competi- 


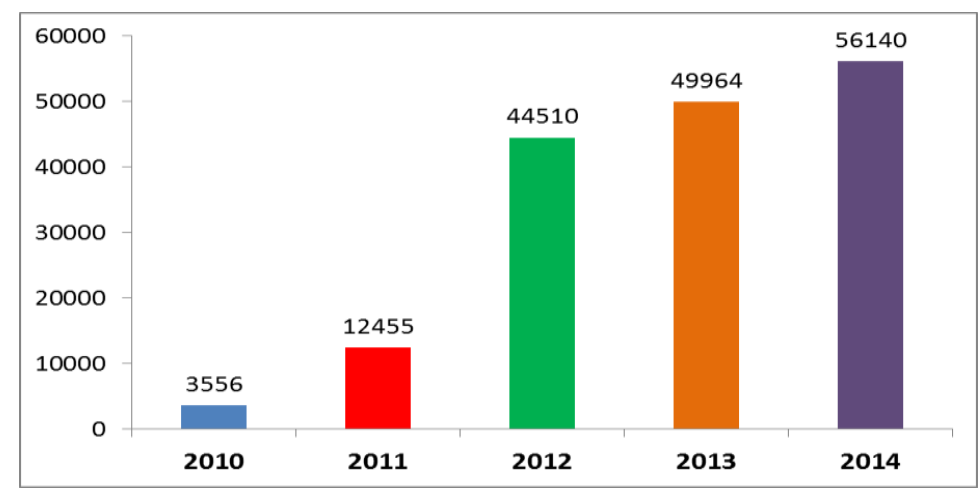

Fig. 1. Submitted solutions on the MENDO grading system.

tions which utilize an automated grading system is not always the perfect option, as it can have several downsides: it requires resources (ie. a computer for each student, servers, etc.), low insurance that students solve the tasks by themselves (for online competitions), difficulties with making sure students have the same environment on their computers as is used on the competition grading system and persuading students to participate in a competition that requires having a specific prior knowledge and abilities, to list the most common. The work presented in (Stankov et al., 2013) addresses some of the above mentioned issues, and there we explore one alternative way of assessment of the contestants' solutions.

In the case of the national contest cycle organized by the Computer Society of Macedonia (and we believe similar problems exist at other countries as well), the biggest issues we face are attracting young students, and providing an initial selection between them. Currently, the problem of attracting students is confronted by visits to schools and organization of promotional events there. Additionally, the promotion is done through teachers which have been involved in earlier contest cycles. Most importantly, we try to keep the pupils online community active during the year using the MENDO platform, and we inform them about the upcoming events.

The first competition that students participate in is the School Contest, which is used by schools to select the best pupils, which they can later send to the Regional Contest. However, organizing a competition like this has the downside of requiring schools to make internal preparations for organizing such a competition (so some schools simply decide not to do it), as well as that each school has an assigned quota (number) of participants they can send to the Regional Contest (which may not be an accurate estimate of skills compared to other schools). Therefore, it is important for us to analyse other possible contest types (presented in the next section), the advantages and disadvantages of each of them, and to try and improve the current process that we use for selecting students early on in the competition cycle.

Besides the official contests for primary and secondary school organized by the Computer Society of Macedonia, there are other contests organized in our country. Some of the more popular competitions, which are based on solving algorithmic tasks, are 
the CodeFu competitions (multiple contests each year), and the ACM-ICPC national competition. The CodeFu competitions are organized using specific rules ( 5 tasks, each worth different number of points), and the ACM-ICPC national competition is organized according to the ACM-ICPC rules. A large number of students who have programming abilities (both on high school and university level) also participate at other competitions - like Startup Weekend Skopje, where they work in teams with other students.

\section{Approaches for Conducting an Initial Selection of Students}

National competitions in informatics are important - both in terms of selecting the best students that will later represent the country at international competitions in informatics, as well as in terms of promoting informatics locally. Agreeing on a system for the national competitions in informatics is one of the first things to consider when starting a new competition cycle. In our experience, the most important thing that should be considered is how the initial selection of students should be done (which is the first real contact that participants have with the competitions). Different approaches have their own advantages and disadvantages. For example, allowing more students in the initial stages of the competitions poses a significant logistical problem - tasks, access to computers, greater number of people involved in the organization of the competitions, travel expenses, etc. These problems are more pronounced in diverse countries such as Macedonia - having multiple ethnic cultures, with students who want to participate using their own mother tongue. On the other hand, limiting the number of students (per school, or per municipality) means that lower number of students will benefit from the organization of the competitions.

In the following list, we present several options for conducting the initial selection of students. Later, we discuss possible strategies for alleviating some of the potential issues, and several approaches for making the competitions more fair and interesting.

- Solving programming tasks (online) - this approach is currently used by a significant number of countries in the IOI community. The biggest advantage of having an online competition organized in such a way is that there is (practically) no limit to the number of participants that can take part in the competition. Also, since one of the main goals of the organizations that are part of the IOI community is to select the best students for international competitions, having a competition in which students solve IOI-style programming problems is an optimal way to select the students which are good in solving such tasks. One example of this approach is USACO (USA Computing Olympiad), which invites students to an on-site camp (where the IOI team is selected) based on the results of web-based contests organized throughout the year, and the performance of students on their on-line training pages (Kolstad and Piele, 2007). The two biggest disadvantages in organizing these types of competitions are that students must have previous experience with solving these types of tasks, as well as the difficulty involved in making sure that students are graded solely on their performance (that they aren't cheating). 
- Solving programming tasks (onsite) - this approach is currently used by many countries. Similarly to the previous option, students solve programming tasks on a computer, but this time - all of them are gathered at one (or multiple) onsite locations - in contrast with solving the tasks online (from home or school). Due to the serious logistical problems in organizing such competitions (organizing staff at every location, a computer for every participant, etc.), only a limited number of students can be accepted to participate at such competitions. On the other hand, the results at such competitions can be taken as official (and a very good estimate of the actual students' abilities). If regulations for issuing certificates imply that competitions must be organized onsite (and are imposed by governing institutions in the country), this approach may be the best alternative to the online competitions mentioned above. The problem of pre-selection of the students can be delegated to the teachers in Informatics in every school. The Macedonian model features a fixed number of places for competitors per school (between 2 and 5, determined every year at the beginning of the cycle), and additional number of places (determined by the number of high achieving students from that school in the previous year's cycle).

- Solving tasks using pen and paper - in many countries that organize different types of contests, these are by far the competitions that attract the highest number (and the most diverse group) of students - a good example is given in (Clark and Clapper, 2014). Although these competitions are very different from the IOI (thus, they cannot be used to select students for international competitions), the biggest advantages they have is that there is no need for hardware resources, but the competitions can include tasks and/or questions of diverse difficulty and types (from solving multiple-choice questions to writing and analysing programs). One of the biggest issues with the previous two options (solving programming tasks on a computer) is that less-experienced students can hardly solve any of the problems - because their solutions are checked using a computer, they usually receive a very low number of points. On the other hand, pen and paper rounds are usually checked by people (teachers), which end up posing logistical problems of their own. We believe that organizing a pen and paper competition is a very good choice if organizations would like to attract more students to computer science.

If organizations have enough resources to support multiple competition types, we believe that it is a very good idea to organize both onsite programming competitions where students work on IOI-style tasks, and contests (or events) that are specifically designed to promote informatics. Besides organizing a custom-made pen and paper round, there are other very good choices that are currently expanding to multiple countries. One such example is the Bebras competition - an initiative that promotes Computational Thinking among pupils. The contests can be organized during normal school hours - thus allowing a very large percentage of students to take part.

On the other hand, there are multiple approaches that can be taken to mitigate the issues with online and onsite programming contests. Clearly, with regards to making sure that students are ranked solely based on their knowledge and abilities during 
online competitions, there are multiple software systems that can detect plagiarism, analyze students using a web camera, or identify suspicious activities (multiple participants using the same IP address, or one participant using multiple addresses), which can later be investigated manually.

Without sufficient hardware and human resources, onsite competitions are very hard to organize correctly. Even if the number of participants is limited, there are several approaches that can be used to enable organizers to make fair decisions. For example, hard limitations to the number of students that a school can enter into a competition, can be mitigated using results from other online contests (like TopCoder or Codeforces) - inviting students which have done good in other contests, or allowing schools to register more participants based on the results of last-years competitions, for example inviting students who have earned certificates at the national competitions, out of the normal quota.

In Table 3, we summarize approaches organizations may take on to improve the process of organizing a competition by which the initial selection of students is made.

Finally, it's worth mentioning that feedback during competitions can be used as mitigation to the problem of having users who score a low number of points due to lack of experience. Feedback is also very useful for making sure that students who make small mistakes do not end up with a too low number of points. However, having feedback requires additional resources. It needs better hardware, so the submissions can be

Table 3

Summary of the approaches organizations may take to improve the process of organizing a competition by which an initial selection of students can be made

\begin{tabular}{|c|c|c|}
\hline Approach & Advantages & Disadvantages \\
\hline $\begin{array}{l}\text { Organizing com- } \\
\text { petitions onsite }\end{array}$ & Fair results, can issue certificates. & $\begin{array}{l}\text { Requires additional hardware and human re- } \\
\text { sources. }\end{array}$ \\
\hline $\begin{array}{l}\text { Organizing pen } \\
\text { and paper rounds }\end{array}$ & $\begin{array}{l}\text { Attracts a large number of partici- } \\
\text { pants, promotes informatics. }\end{array}$ & $\begin{array}{l}\text { Less programming involved, can't be solely } \\
\text { used to select best competitors for international } \\
\text { competitions. }\end{array}$ \\
\hline $\begin{array}{l}\text { Organizing paral- } \\
\text { lel competitions } \\
\text { (Bebras, etc) }\end{array}$ & $\begin{array}{l}\text { Attracts a large number of partici- } \\
\text { pants, promotes informatics. }\end{array}$ & $\begin{array}{l}\text { Can't be used to select competitors for inter- } \\
\text { national competitions, usually requires hard- } \\
\text { ware and more involvement from teachers. }\end{array}$ \\
\hline $\begin{array}{l}\text { Tasks of varying } \\
\text { difficulty }\end{array}$ & $\begin{array}{l}\text { Tasks are approachable by more stu- } \\
\text { dents. }\end{array}$ & $\begin{array}{l}\text { More tasks need to be created and they must be } \\
\text { ordered correctly in the final set of tasks because } \\
\text { less experienced students have problems in } \\
\text { determining their difficulty. This can be hard to } \\
\text { do, as students can be good at different things. }\end{array}$ \\
\hline $\begin{array}{l}\text { Age categories, } \\
\text { Difficulty divi- } \\
\text { sions }\end{array}$ & $\begin{array}{l}\text { More students can get involved; they } \\
\text { can solve tasks that are designed for } \\
\text { their level of knowledge and ability } \\
\text { (i.e. beginner groups) }\end{array}$ & $\begin{array}{l}\text { Requires additional human resources, due to } \\
\text { the need for additional tasks and questions to be } \\
\text { prepared and (potentially) judged. }\end{array}$ \\
\hline $\begin{array}{l}\text { Feedback during } \\
\text { competitions }\end{array}$ & $\begin{array}{l}\text { Results are more fair, as small mis- } \\
\text { takes don't lead to drastic changes in } \\
\text { results (unless the student is not able } \\
\text { to debug - identify or fix mistakes). }\end{array}$ & $\begin{array}{l}\text { It must be ensured that test cases and solutions } \\
\text { (i.e. the feedback) are correct and they adhere to } \\
\text { the task description. }\end{array}$ \\
\hline
\end{tabular}


graded in real time. Also, it requires significant preparations before the contests, which demands a greater team of people who will work on tasks. Having an incorrect official solution, test cases, or grading system during such competitions that allow feedback, can lead into doubt of the fairness of the entire competition, due to the incorrect notifications given to students.

\section{Conclusion}

Competitions are a very important part of education. Given the rise of informatics and computer science in the world, multiple organizations are using competitions to promote informatics to a diverse group of young students. Today, there are many national and international competitions in informatics being organized each year - some of them having different rules and regulations. Some of the most popular international competitions in informatics are the International Olympiad in Informatics, ACM-ICPC, Google Code Jam and Bebras.

In this paper we identified several criteria for reviewing different competitions in informatics, depending on what participants need to work on, the duration of the competition and the type of grading done, the scoring system, what participants need to deliver, how they will provide their output or product, and the type of feedback given during the actual competition.

The most critical part of creating a national contest cycle is defining the parameters to which the initial selection of students will comply. Popular mechanisms used as an initial contact with students are online (or onsite) programming competitions and pen and paper rounds. In the paper, we have explored different approaches with their advantages and disadvantages, and we tried to give a summary that can be useful to organizations that will organize contests in the future, or to organizations that are planning to introduce changes in their current competition cycles.

Also, we have tackled the issue of increasing the number of participants in the competitions. Using strategies like: making stronger connections with teachers, organizing Bebras-style competitions, tracking (sustaining of an online community using apps or social media) and appropriately awarding users who introduce other people to the competitions in informatics, can be very helpful. Age divisions, feedback, valuing results at other competitions and organizing parallel events to promote informatics are just some of the things that organizations can use to further engage students to the art of computer science.

\section{Acknowledgement}

The research presented in this paper is partly supported by the Faculty of Computer Science and Engineering in Skopje. 


\section{References}

ACM International Collegiate Programming Contest (ACM-ICPC) (2015).

http: / / icpc.baylor.edu/

Bebras - International Contest on Informatics and Computer Fluency (2007-2015).

http: //bebras.org

Clark, D., Clapper, M. (2014). The Australian Informatics Competition (AIC). Olympiads in Informatics, 8, 179-189.

CodeFu Coding Competition (2015). http: / / codefu.mk

Computer Society of Macedonia. http:// zim.mk

Goodhew, G. (2009). Meeting the Needs of Gifted and Talented Students. London, Continuum International Publishing Group.

Google Code Jam (2008-2015). https: / / code.google.com/codejam

Infomatrix (2015). http: / / www. infomatrix.ro/

International Olympiads in Informatics (IOI) (1989-2015). http: / / www . ioinformatics . org

Jovanov, M., Kostadinov, B., Stankov, E., Mihova, M., Gusev, M. (2013). State competitions in informatics and the supporting online learning and contest management system with collaboration and personalization features MENDO. Olympiads in Informatics, 7, 42-54.

Kolstad, R., Piele, D. (2007). USA computing olympiad (USACO). Olympiads in Informatics, 1, $105-111$.

Kostadinov, B., Jovanov, M., Stankov, E. (2010). A new design of a system for contest management and grading in informatics competitions. In: ICT Innovations Conference 2010, Web Proceedings. 87-96.

Magdin, M., Turcani, M. (2015). A few observations and remarks on time effectiveness of interactive electronic testing. Informatics in Education, 14(1), 83-102.

Pohl, W. (2006). Computer science contests for secondary school students: approaches to classification. Informatics in Education, 5(1), 125-132.

Stankov E., Jovanov M., Madevska Bogdanova A., Gusev M. (2013), A new model for semiautomatic student source code assessment. CIT. Journal of Computing and Information Technology, 21(3), 185-194.

Verhoeff, T. (1997). The role of competitions in education. In: Future World: Educating for the $21^{\text {st }}$ Century: a conference and exhibition at IOI 1997.

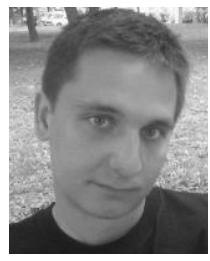

B. Kostadinov is currently working as a software engineer. In 2014, he defended his MSc thesis in Intelligent information systems at the Faculty of Computer Science and Engineering, University "Ss. Cyril and Methodius", in Skopje. He is one of the organizers of the Macedonian national competitions in informatics. He has participated at IOI as a contestant and also as a team leader for the Macedonian team. 
M. Jovanov is an assistant professor at the Faculty of Computer Science and Engineering, University "Ss. Cyril and Methodius", in Skopje. As the President of the Computer Society of Macedonia, he has actively participated in the organization and realization of the Macedonian national competitions and Olympiads in informatics since 2001. He has been a team leader for the Macedonian team at International Olympiads in Informatics since 2006. His research interests include development of new algorithms, future web, and e-education, and he has authored more than 40 research peer reviewed papers.

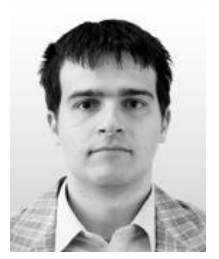

E.Stankov is a teaching and research assistant at the Faculty of Computer Science and Engineering, University "Ss. Cyril and Methodius", in Skopje. He is a member of the Executive Board of the Computer Society of Macedonia, and has actively participated in the organization and realization of the Macedonian national competitions and Olympiads in informatics since 2009. Currently he is a Ph.D. student at the Faculty of Computer Science and Engineering. His research includes analysis of program code correctness using different techniques, and its application to e-learning.

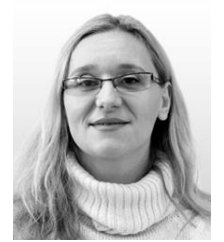

M. Mihova is an associate professor at the Faculty of Computer Science and Engineering, University "Ss. Cyril and Methodius", in Skopje. She is a member of the board of the Computer Society of Macedonia. Her research interest is in the field of applied mathematics, more specifically applied probability and statistics, with focus on mathematical models in reliability, especially reliability of multi-state systems.

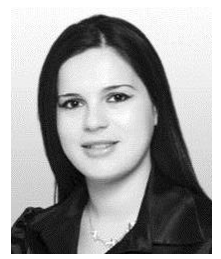

B. Risteska Stojkoska obtained her Ph.D. degree in 2013 with the thesis "Data fusion in wireless sensor networks." Currently she works as an Assistant Professor at the Faculty of Computer Science and Engineering (FCSE), University "Ss. Cyril and Methodius", Skopje, Macedonia. She is an author of more than 30 peer reviewed papers. Her research interests include positioning in wireless sensor networks; smart home; smart grid; wireless power transmission; and intelligent and embedded systems. She serves as TCP member of more than 10 international conferences. 
